\title{
Emergence of fluoroquinolones-resistant strains of Salmonella typhi: Watch on multidrug-resistant isolates
}

This article was published in the following Dove Press journal:

Pathology and Laboratory Medicine International

3 May 2010

Number of times this article has been viewed

\section{Subhash C Arya \\ Nirmala Agarwal \\ Shekhar Agarwal \\ Dolly Wadhwa}

Sant Parmanand Hospital, Delhi, India

Correspondence: Subhash C Arya Sant Parmanand Hospital, 18 Alipore Road, Delhi I I 0054, India

Email subhashhapaji@gmail.com
Emergence of multidrug-resistant Salmonella typhi has been responsible for clinical challenges for clinicians. Recently, frequent isolation and dissemination of fluoroquinolones-resistant strains of S. enterica in Surabaya, Indonesia was in the news. Subsequently, Yangai and colleagues ${ }^{1}$ recommended regular communications between laboratory professionals and clinicians. Collaboration between laboratory personnel and clinicians would be essential to offer a rational empiric antibiotic recipe while awaiting antibiotic susceptibility test results (AST) for any patient.

This type of collaboration has been practiced at Sant Parmanand Hospital, a private, 140-bed, tertiary care, multidisciplinary hospital in Delhi, India for the past four years. From 2004, the antibiotic susceptibility profiles of clinical isolate including S. typhi have been observed and shared with clinicians. Specimens were cultured on MacConkey's agar, heated blood agar, and mannitol salt agar. After 48 hours of incubation, colonies were identified using morphological, biochemical characters and/or slide agglutination. AST assays were performed on Müller-Hinton plates using the agar diffusion technique using BBL ${ }^{\mathrm{TM}}$ Sensi-Disc ${ }^{\mathrm{TM}}$ Antimicrobial Susceptility Test Discs (Becton Dickinson Diagnostic Systems, Sparks, MD). The interpretations, depending on the diameter of the zone of inhibition, were performed according to Clinical Laboratory Standards Institute (CLSI) criteria.

Antimicrobials, oral and systematic, exhibiting a $75 \%$ or more susceptibility in isolates examined were compartmentalized in relation to divergent clinical syndromes. ${ }^{2}$ The retrospective AST data during the period October to December 2004 was the baseline to guide clinicians towards prospective empirical chemotherapy.

During 2004, S. typhi resistance was unknown against the then outstanding antimicrobials. ${ }^{2}$ Subsequently a gradual rise was evident in resistant strains (Table 1 ). The rise in ciprofloxacin-resistant isolates was statistically significant (Fisher's exact test; $P=0.002$ ) while there was no significant change with ofloxacin, amikacin, ceftazidime, or ceftriaxone. The emerging resistance to various antibiotics has been disturbing and is being addressed by swift AST communications to clinicians.

We agree that the cost of antibiotics is important at the primary or secondary health care levels. Nevertheless, it might not be all that important in tertiary care hospitals. Clinicians who normally handle patients with severe clinical manifestations caused by $S$. typhi including fatal septicemia and pyomyositis, ${ }^{3}$ would not be all that worried about the cost of antibiotics offered to such patients. 
Obviously, regular updates on AST results as illustrated above would be useful for clinicians treating $S$. typhi infections to select appropriate antibiotics while waiting and after receiving AST for any patient.

Table I Trends in antibiotic susceptibility of S. typhi isolates and selected antimicrobials*

\begin{tabular}{llll}
\hline Antibiotic & \multicolumn{3}{l}{ Susceptible isolates/total isolates (n and \%) } \\
\cline { 2 - 4 } & $\mathbf{2 0 0 4}$ & 2006 onwards & Fisher's $\boldsymbol{P}$ \\
\hline Ciprofloxacin & $13 / 13(100)$ & $128 / 182(70.3)$ & 0.02 \\
Ofloxacin & $13 / 13(100)$ & $150 / 181(82.8)$ & NS \\
Amikacin & $11 / 11(100)$ & $172 / 178(96.6)$ & NS \\
Ceftriaxone & $7 / 7(100)$ & $93 / 118(78.8)$ & NS \\
Ceftazidime & $9 / 9(100)$ & $106 / 117(90.6)$ & NS \\
\hline
\end{tabular}

Notes: "Discrepancy in the number of isolates tested with nonfluoroquinolones has been due to erratic supply of antibiotic disks (BBL, Sensi-Disk; Becton Dickinson and Company, Sparks, MD) during 2006-2007: Clinical and Laboratory Standards Institute (CLSI) guidelines were used for interpretations.

\section{Disclosures}

The authors report no conflicts of interest or financial support in this work. No ethical clearance was required.

\section{References}

1. Yangai D, de Vries GC, Rahardjo D, et al. Emergence of fluoroquinoloneresistant strains of Salmonella enterica in Surabaya, Indonesia. Diagn Microbiol Infect Dis. 2009;64(4):422-426.

2. Arya SC, Agarwal N, Agarwal S. Straightforward representation of antimicrobial chemotherapeutics susceptibility profiles in a private tertiary care hospital. J Infect. 2005;51(4):333-335.

3. Hsu CC, Chen WJ, Chen SY, Chiang WC, Hsueh PR. Fatal septicemia and pyomyositis caused by Salmonella typhi. Clin Infect Dis. 2004;39(10):1547-1549.
Pathology and Laboratory Medicine International

\section{Publish your work in this journal}

Pathology and Laboratory Medicine International is a peer-reviewed, open access journal focusing on innovative basic research and translational research related to pathology or human disease. The journal includes original research, updates, case reports, reviews and commentaries on current controversies. The Academic Sponsor

\section{Dovepress}

of this journal is the Chinese American Pathology Association (CAPA). The manuscript management system is completely online and includes a very quick and fair peer-review system. Visit http://www.dovepress.com/testimonials.php to read real quotes from published authors.

Submit your manuscript here: http://www.dovepress.com/pathology-and-laboratory-medicine-international-journal 